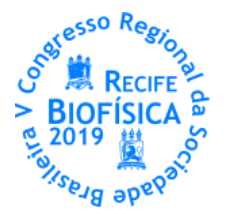

\title{
PROPOSTA DE ALTERAÇÕES EM UM GERADOR DE PULSOS ELÉTRICOS DE CÓDIGO ABERTO PARA CONTROLE DA SECREÇÃO DE INSULINA EM ILHOTAS DE LANGERHANS
}

\author{
José Radamés Ferreira da Silva ${ }^{1}$, Victor Wanderley Costa de Medeiros ${ }^{2}$, Ramón Enrique Ramayo González ${ }^{3}$, Romildo \\ de Albuquerque Nogueira ${ }^{1 *}$
}

\author{
${ }^{1}$ Laboratório de Biofísica Teórico-Experimental e Computacional (LABTEC). Departamento de Morfologia e Fisiologia Animal, Universidade \\ Federal Rural de Pernambuco, 52171-900, Recife, Pernambuco, Brasil. \\ ${ }^{2}$ Departamento de Estatística e Informática, Universidade Federal Rural de Pernambuco, 52171-900, Recife, Pernambuco, Brasil. \\ ${ }^{3}$ Laboratório de Sistemas Complexos e Universalidades. Departamento de Física, Universidade Federal Rural de Pernambuco, 52171-900, \\ Recife, Pernambuco, Brasil. \\ *Autor de correspondência email: ran.pe@terra.com.br
}

\section{INTRODUÇÃO}

O Diabetes Mellitus (DM) é uma doença sistêmica que se caracteriza pela alteração na liberação de insulina através das células B-pancreáticas ou pela redução da absorção da glicose pelas células do organismo por deficiência no transportador de glicose GLUT 4 , que são os mecanismos responsáveis pela alteração nos níveis de glicose no sangue. (BRINKMAN, 2017; COSTABILE; SARNSAMAK; HAUGE-EVANS, 2018; CRAWFORD, 2017; D'ALEO et al., 2011; PEDERSEN et al., 2013; PROF DANEMAN, 2006; RORSMAN et al., 2011).

O tratamento do diabetes do tipo 1 ou 2 pode ser bastante invasivo com a necessidade de várias aplicações diárias de insulina exógena, que causam dores físicas e psicológica. Pode também ser utilizadas drogas para inibir ou estimular a secreção de insulina associadas ou não a insulina (JIAOJIAO et al., 2018). Os indivíduos portadores da doença muitas vezes possuem a massa de células $B$ pancreáticas reduzidas nas ilhotas de Langerhans e as restantes que continuam a secretar insulina, fazem em menor quantidade. (GASTALDELLI, 2011)

A regulação dos níveis de glicose sanguínea é realizada pela parte endócrina do pâncreas que controla a secreção de insulina realizada pelas células beta-pancreáticas ao detectar os níveis elevados de glicose no plasma. (BERTRAM; SHERMAN; SATIN, 2010; CADE; HANISON, 2017; JOUVET; ESTALL, 2017; PEDERSEN, 2007). Para controlar o teor de açúcar no sangue, ocorrem alterações características nas propriedades biofísicas das células beta estimuladas por glicose. São geradas nestas células alterações na permeabilidade da membrana das células beta e, em decorrência disso, despolarizações e repolarizações ocorrem na membrana dessas células, produzindo uma atividade elétrica denominada de burst que controla o processo da secreção da insulina.

A atividade elétrica das células beta depende de canais iônicos e seus mecanismos de gating, sendo a concentração de cálcio $\left(\mathrm{Ca}^{2+}\right)$ no citosol um fator preponderante no controle da secreção da insulina. Durante a fase ativa dos potenciais "bursts", o $\mathrm{Ca}^{2+}$ entra na célula através de canais de cálcio voltagem dependentes, elevando a concentração desse íon. Durante a fase silenciosa, o $\mathrm{Ca}^{2+}$ é removido do citosol por bombas de cálcio, diminuindo sua concentração (CHA; POWELL; NOMA, 2011; FARASHI; SASANPOUR; RAFII-TABAR, 2018; FRIDLYAND; TAMARINA; PHILIPSON, 2010).
Durante a ativação celular gera-se o "Bursting", que significa sequência de disparos na fase ativa do potencial de membrana dependentes das oscilações de cálcio e que está relacionado à secreção de insulina, como foi relatado pela primeira vez em estudos in vitro de ilhotas por Dean e Mathews em 1970 (DEAN; MATTHEWS, 1970). Desde então tem sido rotineiramente observado e bem caracterizado em muitos outros estudos (BERTRAM; SHERMAN; SATIN, 2010). Esses "Burstings" de potenciais são repetitivos e intimamente relacionados com a regulação da glicose induzida por secreção de insulina em células beta-pancreáticas (BARG et al., 2001; CHA; POWELL; NOMA, 2011). Dependendo da quantidade de glicose presente no organismo é necessário um tempo maior para a regulação de seus níveis no sangue, portanto níveis elevados de glicose exigem "Burst" com maior duração de fase ativa causando assim o aumento de sua largura que provoca maior secreção de insulina. (RORSMAN; ASHCROFT, 2018)

Alguns indivíduos podem não ter a capacidade de produzir a secreção necessária de insulina nas células beta. Entretanto, estudos relataram que, indivíduos com resistência à insulina (diabetes não dependente de insulina) apresentam diminuição tanto na massa de células beta, quanto nos grânulos de secreção de insulina (GASTALDELLI, 2011). O Diabetes Mellitus representa uma das principais causas de doenças cardiovasculares, morbidade e mortalidade nos países ocidentais (DAVİ; VAZZANA; SESTILI, 2012), sendo a doença mais devastadora, crônica e não transmissível e que se tornou um sério problema global de saúde (SHEIK ABDULAZEEZ, 2013).

Os métodos químicos de tratamento para a diabetes não são plenamente eficazes e têm efeitos colaterais. Assim, há uma busca óbvia para um tratamento alternativo com métodos adequados (SHEIK ABDULAZEEZ, 2013). A compreensão dos mecanismos de tais efeitos exige desenvolvimento de novos equipamentos e modelos matemáticos que representem adequadamente a dinâmica nas ilhotas pancreáticas. Um dos modelos matemáticos mais estudados é aquele do tipo Hodgkin-Huxley, que foi utilizado por NEVES e colaboradores (2014) para demonstrar que pulsos externos de baixas voltagens influenciam na secreção de insulina, pois favorecem a manutenção da fase ativa "Burst", podendo assim promover maior secreção de insulina. Atualmente, processos de percepção e transdução de sinal por organismos vivos atrai a 
atenção de pesquisadores em vários campos de estudos. Um dos aspectos importantes é a sensibilidade de sistemas vivos a sinais externos de baixa voltagem (NEVES et al., 2014; ZADOROSNY et al., 2015). Construir um aparelho de baixo custo que possa controlar com pulsos de voltagens o funcionamento das ilhotas de Langerhans no processo da secreção de insulina, mostra-se uma alternativa inovadora ao tratamento do DM2. Esta proposta foi motivada pelo estudo teórico que realizamos sobre a relação entre pulsos de voltagens e a resposta elétrica das células beta pancreáticas (GONZÁLEZ; DA SILVA; ALBUQUERQUE NOGUEIRA, 2018).

Portanto, o objetivo do nosso trabalho é construir um gerador de pulsos de voltagem extremamente baixa, bem como desenvolver um sistema experimental que permita estimular ilhotas de Langherans de ratos in vitro.

\section{METODOLOGIA}

Construção de um gerador de pulsos elétricos para controle da secreção de insulina em ilhotas de Langerhans.

A execução dessa proposta será realizada em duas etapas:

1. Adaptação de um gerador de voltagens de baixas amplitudes, com materiais de baixo custo;

2. Desenvolvimento de um sistema experimental que permita a aplicação de pulsos elétricos em ilhotas de Langerhans de ratos in vitro.

Etapa 1: Utilização de um gerador de voltagens de baixas amplitudes, com materiais de baixo custo.

Nos últimos anos, a comunidade científico-tecnológica propôs uma plataforma eletrônica de código aberto, denominada "Arduino", para monitorar e controlar hardware experimental. Um Arduino é composto por um microcontrolador localizado em uma pequena placa de circuito impresso $(\mathrm{PCl})$ com chip programável. Devido a sua interface amigável e simples de programar e reprogramar, bastando apenas utilizar um cabo USB para transmitir o código que é construído com uma versão simplificada da linguagem de programação C++. O "Arduino" possui muitas aplicações na construção de equipamentos científicos como osciloscópio, sistema de análise de fluxo, colorímetro, análise de amostras por eletroforese capilar e monitoramento de temperatura e umidade (BADAMASI, 2014; D’AUSILIO, 2012; KOENKA; SÁIZ; HAUSER, 2014; PEARCE, 2012).

Para construir o gerador de função foi utilizada como base a placa de circuito impresso do "Pulse Pal" versão 2.0 (Figura 1), que é um gerador de trem de pulsos de código aberto de baixo custo, cujo os componentes para sua montagem são obtidos com facilidade (SANDERS; KEPECS, 2014).

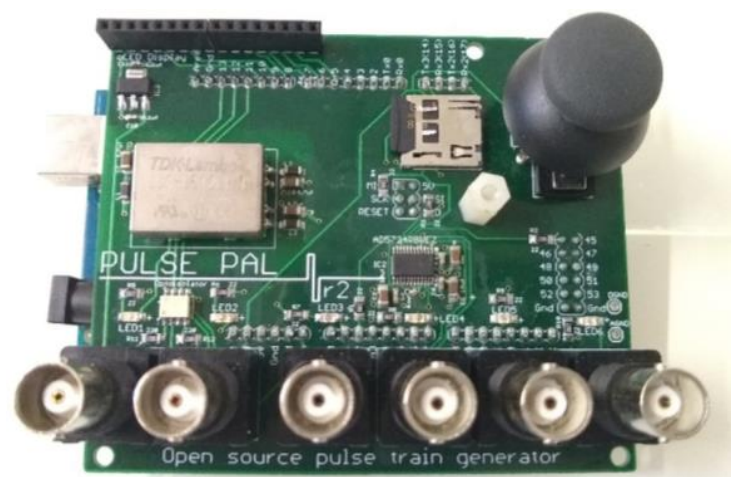

Figura 1: Placa de circuito impresso do "PULSE PAL".

O Pulse Pal passa os sinais lógicos do acionador de entrada através de um circuito incorporado (IC em inglês) que possui função semelhante a um fusivel protegendo os pinos de entrada do microcontrolador. Os sinais de disparo são então lidos pelo microcontrolador ARM Cortex M3 da Pulse Pal. 0 microcontrolador gera formas de onda analógicas controladas por conversor digitalanalógico (DAC em inglês) de 4 canais (AD5724RBREZ-ND, na versão 2.0), configurado com circuitos de saída bipolar. Este circuito de saída consiste em um amplificador operacional (TL084ACN, Texas Instruments) e dois resistores de 10k (R3, R4) que dividem a tensão de referência do DAC, fornecendo coletivamente voltagens de saída na faixa de -10 a $+10 \mathrm{~V}$ de cada (unipolar) canal de saída do DAC. 0 circuito de disparo e estimulação do "Pulse Pal" para um único canal de saída de disparo analógico é mostrado na figura 2 , o mesmo circuito se aplica a todos os 4 canais. (SANDERS; KEPECS, 2014)

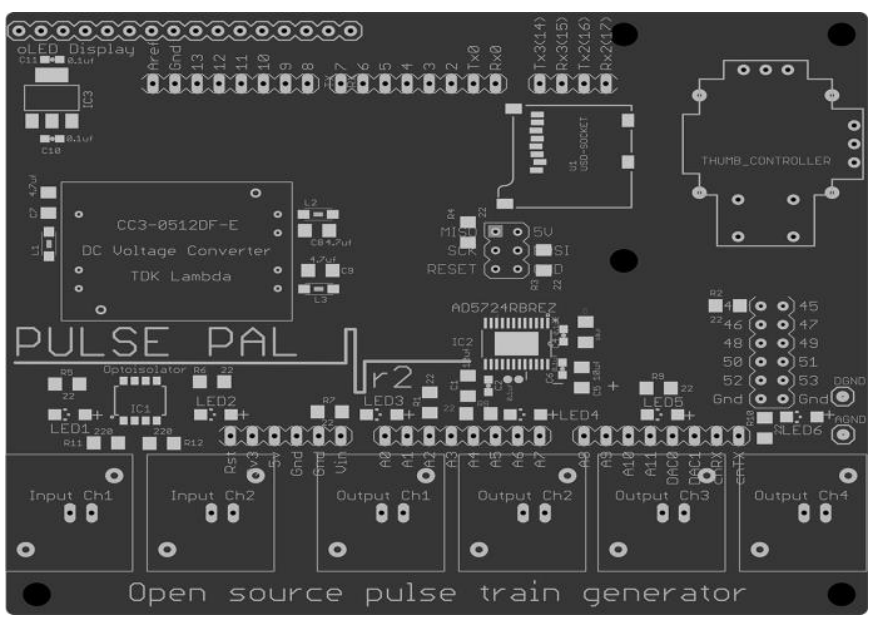

Figura 2: Placa de circuito impresso. Apresenta a localização exata de todos os componentes eletrônicos que compõem o aparelho, facilitando a sua montagem e soldagem. Fonte (SANDERS; KEPECS, 2014)
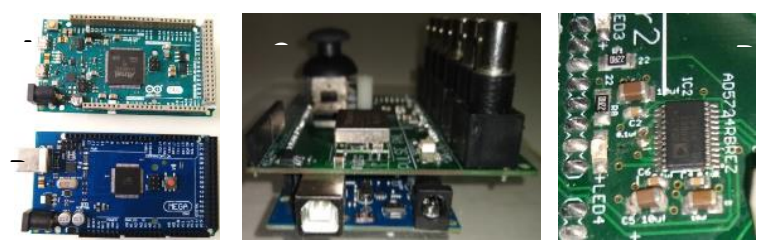

Figura 3. Projeto do gerador de pulsos: o DAC original do Pulse Pal foi trocado pelo AD5754RBREZ-ND que possui 16 bits disponíveis, trazendo com isso maior precisão e controle das voltagens de saída.

Para aplicar nossos estímulos trocamos o DAC original do Pulse Pal pelo AD5754RBREZ-ND que possui 16 bits disponíveis trazendo com isso maior precisão e controle das voltagens desejadas. Isso permitiu que o mesmo pudesse emitir pulsos em milivolts $(\mathrm{mV})$, necessários para nosso experimento, também trocamos o Arduino DUE original do projeto por uma Arduino Mega por uma questão de compatibilidade da placa com as bibliotecas utilizadas no código mais simples que foi escrito para aplicação dos pulsos. Tais alterações podem ser visualizadas na figura 3 .

Etapa 2: desenvolvimento de um sistema experimental que permita a aplicação de pulsos elétricos em ilhotas de Langerhans de ratos in vitro.

\section{A extração do pâncreas}

Para retirada do pâncreas, os ratos devem ser eutanasiados por aprofundamento anestésico com associação de cetamina 75 . $100 \mathrm{mg} / \mathrm{Kg}$ e xilazina $5-10 \mathrm{mg} / \mathrm{Kg}$ em dosagem 2 vezes acima da recomendada para anestesia por via intraperitoneal (LANG et al., 1987; PENICAUD et al., 1987). Em seguida o rato deve ser posicionado em decúbito ventral com as patas em extensão e realizada a tricotomia e antissepsia do campo cirúrgico com etanol 
a 70\%, após esterilização deve ser realizada uma incisão ao redor do abdome superior para expor o fígado e os intestinos visando a perfusão com colagenase tipo XI (1000 Uml-1) dissolvida em 1 parte de HBSS (LI et al., 2009), para distender o pâncreas e facilitar posteriormente sua remoção para isolamento das ilhotas de Langerhans.

$\mathrm{Na}$ perfusão a ampola será pinçada utilizando uma pinça hemostática curvada, em seguida uma injeção lenta da primeira metade da solução colagenase $V$ é aplicada no ducto biliar comum através da articulação do ducto hepático e do ducto cístico, posteriormente, a velocidade de injeção é aumentada e ao final o pâncreas distendido é coletado a partir do duodeno e evitando ao máximo o aglomerado de tecido adiposo.

\section{Isolando as ilhotas de Langerhans}

Após ser removido o pâncreas deve ser colocado num tubo Falcon de $50 \mathrm{ml}$, contendo solução de colagenase e levado ao banho-maria a $37.5^{\circ}$ C por 15 min para digestão dos tecidos em volta do pâncreas, sendo agitado brevemente por duas a três vezes manualmente durante o tempo de incubação. Após a incubação, o tubo deve ser agitado vigorosamente com a mão para romper o pâncreas até que a suspensão fique homogênea.

Terminada a digestão o tubo deve ser colocado em gelo e adicionada solução de $\mathrm{CaCl} 2(1 \mathrm{mM})$ dissolvido em 1 parte de HBSS, e posteriormente, centrifugada a $290 \mathrm{~g}$ durante $30 \mathrm{~s}$ a $4{ }^{\circ} \mathrm{C}$ e o sobrenadante descartado. Em seguida, deve ser ressuspendidos $\mathrm{o}$ sedimento com solução de $\mathrm{CaCl}_{2}$ gelada, e centrifugado novamente a $290 \mathrm{~g}$ durante $30 \mathrm{~s}$ a $4{ }^{\circ} \mathrm{C}$ sendo descartado o sobrenadante.

Os sedimentos devem ser ressuspendidos com solução de $\mathrm{CaCl}_{2}$ para filtragem em uma peneira de células de $70 \mu \mathrm{m}$.

As ilhotas capturadas na filtragem devem ser transferidas para uma placa de Petri com $30 \mathrm{ml}$ de uma solução de L-glutamina $(20 \mathrm{mM})$, penicilina $\left(100 \mathrm{Uml}^{-1}\right)$, estreptomicina $\left(100 \mu \mathrm{gml}^{-1}\right)$ e FBS $(10 \%)$, em meio de cultura RPMI 1640, posteriormente, as ilhotas de Langerhans devem ser incubadas a $37^{\circ} \mathrm{C}$ suplementada com $5 \%$ $\mathrm{CO}_{2}$.

\section{A aplicação de pulsos elétricos nas ilhotas}

Após $12 \mathrm{~h}$ de incubação o soro com as ilhotas deverá ser transferido para tubos de Eppendorf com capacidade para $2 \mathrm{ml}$ visando a aplicação dos pulsos elétricos nas ilhotas. Após a aplicação de pulsos com equipamento construído nesse trabalho medem-se os níveis de insulina nos poços estimulados e não estimulados. Este protocolo permitirá avaliar a secreção de insulina em resposta aos pulsos elétricos.

Para obtenção dos níveis de secreção de insulina pelas ilhotas de Langerhans deve ser usado um espectrofotômetro UV/VIS utilizando um comprimento de onda variando entre $260-300 \mathrm{~nm}$ para quantificar a insulina secretada.

0 objetivo desse procedimento in vitro foi parametrizar a secreção da insulina frente aos pulsos de voltagens visando à construção de um sistema elétrico que possa controlar a secreção de insulina no pâncreas.

\section{RESULTADOS E DISCUSSÃO}

0 equipamento gerador de pulsos construído foi testado em osciloscópio (RIGOL 5102M), para verificarmos se os pulsos de baixa voltagem programados no Arduino estavam realmente saindo do equipamento. Inicialmente fizemos o teste das conexões do aparelho com o computador (figura 4) para compilar e transmitir o código para o Arduino e por sua vez gerar os pulsos de baixa voltagem.

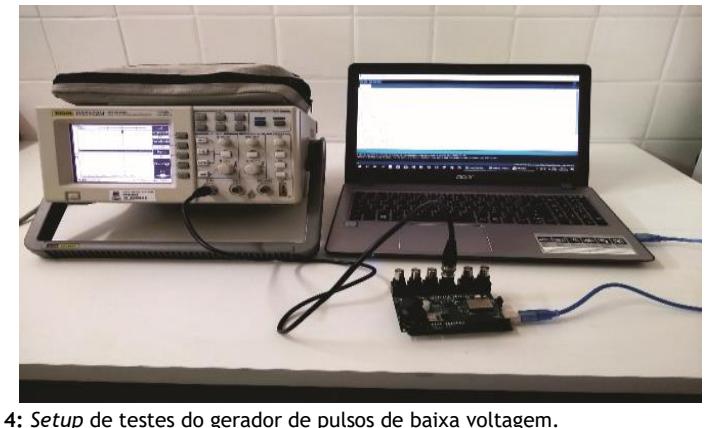

Figura 4: Setup de testes do gerador de pulsos de baixa voltagem.

Em seguida iniciamos o processo de configuração do equipamento para emitir em cada uma das 4 saídas de diferentes valores de pulsos simultâneos, sendo necessário esse procedimento para ajustar os valores inteiros que serão interpretados pelo DAC para emissão dos pulsos de baixas voltagens. Podemos observar que o є ‘juipamento funcionou plenamente emitindc os pulsos de baixas voltagens. Na Fig 5 pode ser observado três diferentes valores médios de voltagens ao longo do tempo.

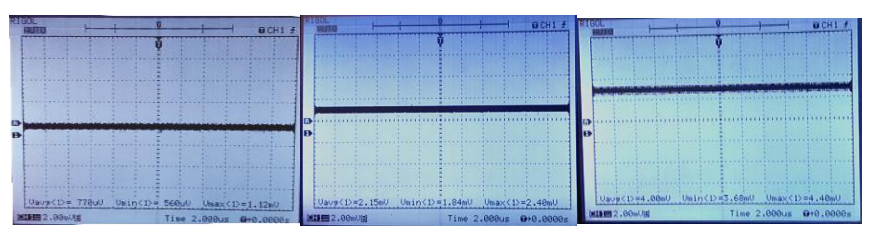

Figura 5: Pulsos elétricos de baixa voltagem. (A) Pulso de 0,77 mV, (B) pulso de 2,15 mV e (C) pulso de $4 \mathrm{mV}$.

Na Fig. 5 pode-se observar um pulso de $0,77 \mathrm{mV}$ muito próximo a linha de base $(0 \mathrm{mV})$, um pulso de $2,15 \mathrm{mV}$ e um outro de $4 \mathrm{mV}$. Esses resultados mostram que o gerador de pulso para baixas voltagens está funcionando adequadamente, e pode ser usado no sistema experimental para aplicação dos pulsos elétricos nas ilhotas de Langerhans de ratos in vitro, que será a próxima do projeto.

\section{CONCLUSÃO}

Como perspectiva futura o nosso grupo pretende testar o equipamento construído realizando o protocolo experimental aqui proposto para comprovar a viabilidade do equipamento como forma alternativa para o tratamento do diabetes menos invasiva que o tratamento convencional com insulina exógena.

\section{AGRADECIMENTOS}

Agradecemos e à Coordenação de Apoio a Pessoal de Nível Superior - CAPES pelo suporte financeiro e ao Centro de Apoio a Pesquisa (CENAPESQ) da UFRPE pelo uso do Laboratório de Análise Computacional e Realidades Complexas (LACREC).

\section{Referências}

BADAMASI, Y. A. The working principle of an Arduino. 2014 11th International Conference on Electronics, Computer and Computation (ICECCO). Anais...IEEE, set. 2014Disponível em: <http://ieeexplore.iee.org/document/6997578/>

BARG, S. et al. Fast exocytosis with few $\mathrm{Ca2}+$ channels in insulinsecreting mouse pancreatic $B$ cells. Biophysical Journal, v. 81, n. 6, p. 3308-3323, 2001.

BERTRAM, R.; SHERMAN, A.; SATIN, L. S. Electrical bursting, calcium oscillations, and synchronization of pancreatic islets. Adv Exp Med Biol, n. 10, p. 261-279, 2010.

BRINKMAN, A. K. Management of Type 1 Diabetes. Nursing Clinics of North America, v. 52, n. 4, p. 499-511, 2017.

CADE, J. E.; HANISON, J. The pancreas. Anaesthesia and Intensive 
Care Medicine, v. 18, n. 10, p. 527-531, 2017.

CHA, C. Y.; POWELL, T.; NOMA, A. Analyzing electrical activities of pancreatic?? cells using mathematical models. Progress in Biophysics and Molecular Biology, v. 107, n. 2, p. 265-273, 2011. COSTABILE, A.; SARNSAMAK, K.; HAUGE-EVANS, A. C. Coffee, type 2 diabetes and pancreatic islet function - A mini-review. Journal of Functional Foods, v. 45, n. January, p. 409-416, 2018.

CRAWFORD, K. Review of 2017 Diabetes Standards of Care. Nursing Clinics of North America, v. 52, n. 4, p. 621-663, 2017.

D'ALEO, V. et al. Direct effects of rapid-acting insulin analogues on insulin signaling in human pancreatic islets in vitro. Diabetes and Metabolism, v. 37, n. 4, p. 324-329, 2011.

D'AUSILIO, A. Arduino: a low-cost multipurpose lab equipment. Behavior research methods, v. 44, n. 2, p. 305-13, jun. 2012.

DAVİ, G.; VAZZANA, N.; SESTILI, S. Variability in the response to antiplatelet treatment in diabetes mellitus. Prostaglandins \& other lipid mediators, v. 98, n. 3-4, p. 48-55, 2012.

DEAN, B. Y. P. M.; MATTHEWS, E. K. MATTHEWS From. p. 265-275, 1970.

FARASHI, S.; SASANPOUR, P.; RAFII-TABAR, H. Interaction of Low Frequency External Electric Fields and Pancreatic B-Cell: A Mathematical Modeling Approach to Identify the Influence of Excitation Parameters. International Journal of Radiation Biology, v. 0, n. 0, p. 1-33, 2018.

FRIDLYAND, L. E.; TAMARINA, N.; PHILIPSON, L. H. Bursting and calcium oscillations in pancreatic beta-cells: specific pacemakers for specific mechanisms. American journal of physiology. Endocrinology and metabolism, v. 299, n. 4, p. E517-32, 1 out. 2010.

GASTALDELLI, A. Role of beta-cell dysfunction, ectopic fat accumulation and insulin resistance in the pathogenesis of type 2

diabetes mellitus. Diabetes Research and Clinical Practice, v. 93, n. SUPPL. 1, p. S60-S65, 2011.

GONZÁLEZ, R. E. R.; DA SILVA, J. R. F.; ALBUQUERQUE NOGUEIRA, R. Effects of External Voltage in the Dynamics of Pancreatic BCells: Implications for the Treatment of Diabetes. In: Bioinformatics and Biomedical Engineering. [s.l.] Springer, Cham, 2018. v. 10813p. 57-70.

JIAOJIAO, Y. et al. Applying emerging technologies to improve diabetes treatment. Biomedicine and Pharmacotherapy, v. 108, n. September, p. 1225-1236, 2018.

JOUVET, N.; ESTALL, J. L. The pancreas: Bandmaster of glucose homeostasis. Experimental Cell Research, v. 360, n. 1, p. 19-23, 2017.

KOENKA, I. J.; SÁIZ, J.; HAUSER, P. C. Instrumentino: An opensource modular Python framework for controlling Arduino based experimental instruments. Computer Physics Communications, v. 185, n. 10, p. 2724-2729, out. 2014.

LANG, C. H. et al. Alterations in glucose kinetics induced by pentobarbital anesthesia. Am J Physiol Endocrinol Metab, v. 253, n. 6, p. E657-663, 1 dez. 1987.

LI, D.-S. et al. A protocol for islet isolation from mouse pancreas. Nature Protocols, v. 4, n. 11, p. 1649-1652, 2009.

NEVES, G. F. et al. $60 \mathrm{~Hz}$ electric field changes the membrane potential during burst phase in pancreatic B-cells: in silico analysis. Acta biotheoretica, v. 62, n. 2, p. 133-43, jun. 2014.

PEARCE, J. M. Building Research Equipment with Free, OpenSource Hardware. Science, v. 337, n. 6100, p. 1303-1304, 2012.

PEDERSEN, M. G. Phantom bursting is highly sensitive to noise and unlikely to account for slow bursting in B-cells: Considerations in favor of metabolically driven oscillations. Journal of Theoretical Biology, v. 248, n. 2, p. 391-400, 2007.

PEDERSEN, M. G. et al. Complex patterns of metabolic and $\mathrm{Ca}^{2+}$ entrainment in pancreatic islets by oscillatory glucose. Biophysical journal, v. 105, n. 1, p. 29-39, 2 jul. 2013.
PENICAUD, L. et al. Effect of anesthesia on glucose production and utilization in rats. Am J Physiol Endocrinol Metab, v. 252, n. 3, p. E365-369, 1 mar. 1987.

PROF DANEMAN, D. Type 1 diabetes. The Lancet, v. 367, n. 9513, p. 847-858, 2006.

RORSMAN, P. et al. Electrophysiology of pancreatic B-cells in intact mouse islets of Langerhans. Progress in biophysics and molecular biology, v. 107, n. 2, p. 224-35, nov. 2011.

RORSMAN, P.; ASHCROFT, F. M. Pancreatic B-Cell Electrical Activity and Insulin Secretion: Of Mice and Men. Physiological Reviews, v. 98 , n. 1, p. 117-214, jan. 2018.

SANDERS, J. I.; KEPECS, A. A low-cost programmable pulse generator for physiology and behavior. Frontiers in Neuroengineering, v. 7, n. December, p. 1-8, 2014.

SHEIK ABDULAZEEZ, S. Diabetes treatment: A rapid review of the current and future scope of stem cell research. Saudi Pharmaceutical Journal, v. 23, n. 4, p. 333-340, 2013.

ZADOROSNY, R. et al. Fenomenologia da Supercondutividade e Supercondutores Mesoscópicos. p. 1-12, 2015. 